\title{
How to Develop and Use Sci-tech Information by Editors of Sci-tech Journals in the New Media Age
}

\author{
Lihua Zhao \\ Editorial Department of Journal of Jilin Agricultural University, Changchun 130118, China \\ Zhaolihua2004@126.com
}

Keywords: Sci-tech information; Sci-tech journal; Editor; Literature retrieval; New media

\begin{abstract}
Sci-tech journals are very important carrier of sci-tech information. With the arrival of the new media age, the channel that people obtain sci-tech information has changed greatly, which has brought a great impact on the survival and development of sci-tech journals and has also put forward a new issue for the editors of sci-tech journals. In order to develop and use the sci-tech information and improve the quality of sci-tech journals, this paper discusses the function of information materials in the editing work of sci-tech journals, expounds that the editors of sci-tech journals should strengthen the information consciousness in the new media age and offers the ways for the editors of sci-tech journals to obtain sci-tech information in the new media age, including obtaining information through the websites of the societies and the sci-tech literature database at all levels, obtaining information by means of retrieval tools or exchanging literature data and obtaining information through participating in academic conferences.
\end{abstract}

\section{Introduction}

With the rapid development of science and technology, a new media based on digital network has been developed. This has brought great impact on the survival and development of traditional media, including sci-tech journals [1]. New media has developed on the basis of newspapers, books, radios, televisions and other traditional media and is the disseminating form providing information and entertainment services to users by means of digital technology, network technology, mobile technology, through the Internet, broadband local network, wireless communication network, satellite channels, computers, mobile phones and digital TVs [2-3]. Sci-tech journals are very important carrier of sci-tech information. They are not only important sources for sci-tech workers to collect sci-tech information, but also important media for the exchange of academic ideas, display and preservation of scientific research results[1]. The level and quality of the sci-tech journals directly determine the value of their existence, and affect their social and economic benefit. There is a close relationship between the quality of sci-tech journals and the input and feedback of sci-tech information. If the editors obtain a large amount of information and the quality of information is high, the quality of editing and publishing journals is high. With the arrival of the new media age, the channel that people obtain sci-tech information has changed greatly. In the new media age, the competition for outstanding sci-tech information is more intense [4]. This has brought serious challenges to the survival and development of the sci-tech journals, and also puts forward new and higher requirements for the journal editors. Therefore, how to get more excellent information, develop and use sci-tech information and improve the quality of sci-tech journals is an important issue in front of the editors of sci-tech journals.

\section{The Function of Information Materials in the Editing Work of Sci-tech Journals}

Information Material is the Basis for Selection of the Topic and Soliciting Contributions. The selection of the topic is the first step of the editorial work, which is the basis of improving the quality of the journals. Therefore, when selecting topics, first of all we should understand and grasp the development of previous related disciplines to provide a favorable condition for the research project, then, we need to focus on the purpose of publication, determine whether the topic is novel, whether the academy has pioneering and whether the content has the sense of the times[5]. All these 
require that the editors of sci-tech journals should have a deep understanding of the principles and policies of the national publishing work, grasp the academic research focus and trends and understand the needs of the society and readers. Only a comprehensive understanding and grasp of the situation, can editors put forward the appropriate topics. Otherwise, if the editors don't get enough information materials, it is difficult for them to judge and select the topics.

Reference Function that Information Materials Have in Manuscript Reviewing. Manuscript review is the review and evaluation of the quality of the manuscripts provided by the authors, so as to determine whether the manuscripts have publishing value. Manuscript review is the key to ensure the academic quality of journals, and it is also the central link of editing work. When reviewing, editors can't miss unqualified manuscripts or neglect valuable papers. First of all, the editors should examine whether the paper is in line with the principles and policies of the publication of the work of the state from a political point of view and whether it is in accordance with the purpose of this publication. Then, editors should determine the academy of the manuscript to judge whether it has put forward new ideas, opened up a new research field, had a certain originality or demonstrated the new argument provided by new materials and new methods etc. [6]. This requires the editors of journals to read a variety of information and make comparison and identification repeatedly to select high quality manuscripts.

Auxiliary Function that Information Materials Have in the Process of Editing and Proofreading. The editing and processing of manuscripts is an important step of the editing work. Processing manuscripts directly affects the quality of journals. Editing and processing is a very serious and careful work, which requires the editors to have a high sense of responsibility and a high moral character to serve others. In the process of editing manuscripts, in order to avoid inaccurate understanding and improper measures, the editors should check the writing background of the manuscripts, the main evidences, the citation sources and the technical terms used in the paper, terminology, historical events and the relevant data, etc. It is especially important to verify the citation and source which is an important part of editing and processing for some manuscripts with serous textual information [5, 6, 7]. Proof reading is the continuation and deepening of the editing process, needs to be taken seriously. In addition to check whether the contents of the proof are accurate in accordance with the contents of the original manuscripts, the editors also correct words and symbols, punctuation, charts and other errors. Therefore, whether the work is the editing process or proof reading, it needs to find the relevant information materials and make use of the reference books.

\section{The Editors of Journals Should Strengthen Information Consciousness in the New Media Age}

The Editors of Journals and Information Consciousness. The purpose of a series of editing activities carried out by the editors of sci-tech journals is to transmit sci-tech information as quickly and accurately as possible. The whole process of editing activities is to extract, process, analyze, research and deal with information. The information consciousness of the editors of sci-tech journals refers to the editors' sensitivity to sci-tech information and the consciousness of searching, analyzing and judging and absorbing the sci-tech information [8]. Information consciousness requires the editors of sci-tech journals to collect sci-tech information at any time, screen the information collected, extract useful information by discarding the dross and selecting the essence and discarding the false and retaining the true, and process and reorganize the most valuable and the most needed information for readers to quantify, order, integrate and materialize, finally form the information based on journals [9], to convey to readers. In the new age, the content of journal editing work is widening, the task is adding, and the requirement is demanding, which requires the editors of sci-tech journals not only to enhance the information consciousness, but also to have a strong ability to obtain information, to collect sci-tech information through a variety of channels, to enrich their information database, especially to train young people to have the ability to obtain information.

Information Consciousness and the Quality of Journals. Information consciousness of the 
editors of sci-tech journals is reflected by the understanding and evaluation of the information and the new sensitivity of academic trends, insight and judgment etc. [8]. The information consciousness of editors plays an important role in improving the quality of journals. The quality of journals is closely related to the ability of capturing and identifying information [7]. Reviewing is to capture the information with publishing value in manuscripts. As is known to all, the original information is not all useful, if not processed, it may become invalid information. In editing activities, the information consciousness of the editors is very important for the optimization of information, the processing of useful information, the overcoming of useless information, the correcting of wrong information, and the highlighting of applicable information [9]. The editors with stronger information consciousness have a strong sense of sci-tech information and insight and often collect relevant information consciously and actively, constantly expand their information capacity and master more sci-tech information so that they can make the right evaluation and judgment in the editing work and make effective selection and optimization to maximize the dissemination and utilization of journal information and improve the academic quality of journals.

\section{Ways That the Editors of Sci-tech Journals Obtain Information in the New Media Age}

Using New Media to Obtain Sci-tech Information. The new media has changed the channel that people get information. The Internet has become an important channel for people to obtain information because of its rich, instant, convenient, economic and diverse characteristics $[1,10]$. Ways of using new media to obtain information: (1) Obtaining sci-tech information through the conference websites, societies, universities and research institution websites, scientific research project management organizations, project websites and sci-tech literature database such as "China National Knowledge Internet (CNKI)" and "VIP database" [10]. The editors should regularly browse the web sites of different societies of sci-tech journals such as www.cessp.org.cn, www.cujs.com, and jlujs.jlau.edu.cn etc. because these sites are generally equipped with a relatively fixed content columns, such as introduction, constitution and institutions etc. and also have the columns with contents constantly updated such as trends, notices (meetings, training, soliciting, awards, project reporting), conferences, international index etc. The editors can get new trends and information in the industry of sci-tech journals through these sites[11]. (2) Obtaining information using e-mail or QQ. (3)Obtaining information using micro-blog or WeChat.

Using Traditional Media to Obtain Sci-tech Information. Although it is convenient, economical and abundant to obtain sci-tech information using the network, there are also some problems, such as scattered information, high repetition rate, key points being not prominent and the uncertainty. Compared with the new media, the information disseminated through traditional media such as sci-tech journals is integrated, discarded the dross and selected the essential, discarded the false and retained the true, offering reliable, clear and reasonable contents to readers. Even in the current era of media convergence, the advantages of paper-based media can not be replaced by the new media. Reviewing printed media is stricter, information is more perfect, thorough and authentic and the publication of the paper-based media has the stable and continuous characteristics. However, the disadvantages of traditional media are poorer in timeliness than the new media [12]. Ways of obtaining information through traditional media: (1) Obtaining information through literature retrieves. As everyone knows, every carrier with text, graphics and symbols, audio, video and other technical means recording human knowledge or information is referred to as document. Information and literature retrieval is the key to open the treasure house of knowledge and are the most convenient, fastest and effective way to update knowledge, to inherit and learn from predecessors' achievements and experiences [9]. The editors of sci-tech journals must understand and master the scientific document retrieval method and learn to use some important search tools, such as authoritative indexing journals at home and abroad including SCI, EI, Catalog of Chinese Sci- tech Information, National Press Index etc. to obtain the most sci-tech information with the least time. This will achieve a multiplier effect for the editors to update knowledge, to understand the new development of relevant disciplines at home and abroad, new 
trends and new results at any time [9]. (2) Obtaining information directly through exchanging documents and materials. Exchanging their own publications with the publications of other units such as the editorial departments, libraries etc at home and abroad, generally professional journals are offered to each other is also one of the ways for the editors to obtain information. The documents exchanged may be published, internal publications, or information etc. Exchanging documents can not only save time and money, but also benefit the rapid communication of information. The editors can directly get the information relevant with their own discipline, related disciplines and from other editors through browsing and reading the information received purposely and selectively[9]. Reading the contents and abstracts of each issue can generally understand the recent situation of their own discipline. For the editing major, two or three authoritative journals can be ordered by the editorial department such as Acta Editologica, Chinese Journal of Scientific and Technical Periodicals and Chinese Editors Journal. Regular reading these journals is helpful to get the editing information [12].

Obtaining Information by Attending Academic Conferences. Academic conference information belongs to interpersonal communication. Although the range is narrow compared with mass communication, academic information dissemination has the advantage of targeting property because the audience is small and concentrated. It is very efficient way to get the information through the discipline leaders and this can get twice the result with half the effort. Regular browsing some sites can easily get conference information [12]. Academic conference is an important way for scientific researchers to undertake academic exchange, learn form each other, contact one another communicate academic ideas with each other and enhance their friendship. The representatives participating in all kinds of academic conferences are generally well-known experts and scholars in the field of relevant disciplines, and some of the world's leading academic authority and academic leaders. Therefore, If the editors can have the opportunity to participate in these conferences, their direct contact with the researchers not only can understand and grasp the current situation, trends and frontier development of the discipline but also can dynamically discover the author group so that it can be targeted for the selection of projects and tracking of soliciting contributions [9]. Therefore, the editors must go into the teaching and research offices and society to contact teachers and researchers, track the major and key research projects, capture the scientific and research information with breakthrough potential, timely listing in the topic selection plan, to understand the trends of scientific researches in universities and research institutes, especially to understand the scientific research situation of academic leaders, to get the research information that they are studying or preparing with the direction of research, high value of research and reflecting the latest achievements. The editors should actively participate in large-scale academic conferences and attend academic reports, seminars, research results identification, sci-tech information conference and master's and doctoral degree thesis defense meeting etc. to get more information about science and technology. At the same time, the editors should seize the opportune to publicize and introduce their publications to the researchers to attract more excellent manuscripts so as to improve the journal quality and enhance competitiveness of journals.

\section{Conclusion}

In short, the sci-tech journal is an important carrier of sci-tech information, and it is an important medium for the dissemination of scientific research results. Its vitality lies in the sharp capture of sci-tech information and the timely reporting of the frontiers of science. The whole process of the journal editing activities is closely related to the sci-tech information. The arrival of the new media era has brought serious challenges to the survival and development of the sci-tech journals, and also put forward new and higher requirements for the journal editors. To meet the challenges of the new media age, conform to the trend of world science and technology progress, realize the sharing of information resources, publish sci-tech journals with high quality, high level, vitality and competitiveness, journal editors must have a strong information consciousness. This requires the editors of sci-tech journals to enhance the concept of information, strengthen the role of information, 
establish modern information consciousness, learn and apply new media technology, improve the ability to capture information, broaden the channels of information, obtain more outstanding information, develop and use sci-tech information and improve the quality of sci-tech journals and market competitiveness.

\section{References}

[1] W.Z.Chen: How to realize the leap forward development of the traditional science and technology periodicals in the new media era [J]. Chinese Journal of Scientific and Technical Periodicals, Vol. 24 (2013) No. 3, pp. 561-563. (In Chinese)

[2] H.Tao, Q. Zhu and M.H.Song etal.: Status and development strategy of new media application in academic journal publishing[J] Acta Editologica, Vol. 26 (2014) No.6, pp. 589-592. (In Chinese)

[3] M. Zhang and J. Feng: Characteristics of the New Media Age and Its Influence on China [J]. West Leather, (2016) No.4. p.114. (In Chinese)

[4] G.H.Lv, L.Y.Gu and X.F.Wang: Understanding and practice of development of sci-tech journals in omnimedia era [J] Acta Editologica, Vol. 26 (2014) No. S1, pp. 4-6. (In Chinese)

[5] T.B.Cheng: On the Role of Journal Reference Room in Editorial Work [J] Journal of Shijiazhuang University. Vol. 10 (2008) No.2, pp.121-124. (In Chinese)

[6] S.L.Jia: Discussion on the application of data information in Journal editing [J] Heilongjiang Social Sciences, (2001) No.6, pp.76-77. (In Chinese)

[7] H.B.Qiao: The effects of Data Information of Journal on Editing [J]. Journal of Qinghai Normal University (Philosophy and Social Science), Vol. 32 (2010) No. 6, pp.144-147. (In Chinese)

[8] C.P.Liu: Information Consciousness of Academic Journal Editors in Information Era [J]. Journal of Shanxi University (Philosophy \&Social Science), Vol. 29(2006) No.2, pp.138-140. (In Chinese)

[9] J.Liang: Reflection on Strengthening the Information Consciousness of Editors of Sci-tech Journals [J] Journal of Guangxi University (Philosophy and Social Science), Vol.20 (1998) No.3, pp.92-96. (In Chinese)

[10]H.Y.Wu, Z.C.Jiang and F.C.Wei: Importance and ways for young editor of technical journal to master academic trends[J] Acta Editologica, Vol. 25(2013) No.1, pp.83-85. (In Chinese)

[11]H.B.Zhou: Three approaches for editors of sci-tech periodicals to obtaining information and knowledge [J] Acta Editologica, Vol. 23 (2011) No.1, pp.78-80. (In Chinese)

[12]L.Li, X. Z.Chang and Q.H.Liu: Cultivation of Information acquisition ability for junior editors of sci-tech journals [J] Acta Editologica, Vol.27 (2015) No.S1,pp.13-14. (In Chinese) 